\title{
Commentary: Points to ponder--Perioperative antithrombotic therapy in neonates with congenital heart disease...more harm than good?
}

\author{
Mary Patricia Massicotte, MD, MSc, MHSc, and Mary Elisabeth Bauman, BA, RN, MN
}

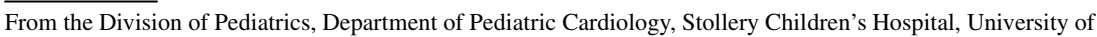
Alberta, Edmonton, Alberta, Canada.

Disclosures: Dr Massicotte is a consultant for the National Institutes of Health/National Heart, Lung, and Blood Institute-funded Pumps for Kids, Infants, and Neonates(PumpKIN) study. Ms Bauman has no conflicts of interest.

Received for publication Feb 12, 2019; accepted for publication Feb 13, 2019; available ahead of print March 20, 2019.

Address for reprints: Mary Patricia Massicotte, MD, MSc, MHSc, Stollery Children's Hospital and University of Alberta, 3-539 ECHA, Edmonton, Alberta, Canada (E-mail: mm41@ualberta.ca).

J Thorac Cardiovasc Surg 2019;157:2414-5

$0022-5223 / \$ 36.00$

Copyright (c) 2019 by The American Association for Thoracic Surgery

https://doi.org/10.1016/j.jtcvs.2019.02.066

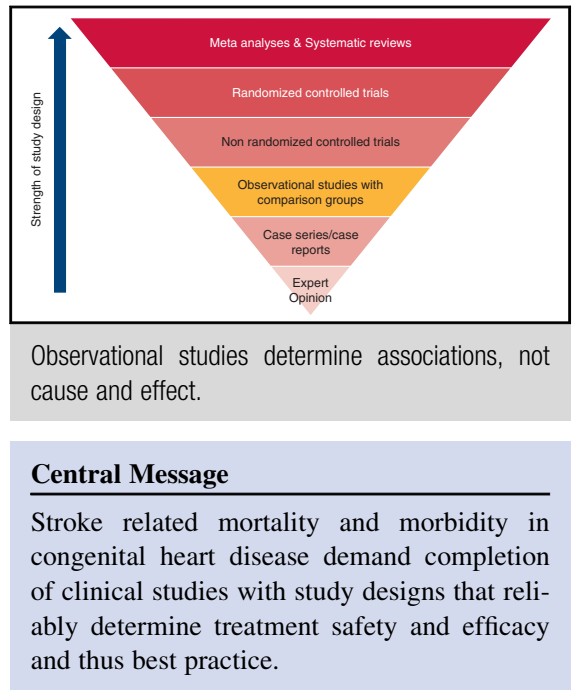

See Article page 2406.
Children with congenital heart disease (CHD) have increased risk of perioperative stroke and brain injury. ${ }^{2}$ In this high-risk cohort, clinicians have used antithrombotic therapy (AT), including anticoagulants or antiplatelet agents, to treat or prevent thrombosis and ischemic stroke. ${ }^{3}$ These therapeutic approaches, however, rely on a single mode of action to modulate hemostasis, inhibiting either thrombin generation or platelet activity, and thus may be too simplistic to modulate the complex balance of hemostasis. Adding to the clinician's dilemma is the paucity of clinical studies in children providing evidence-based recommendations. $^{3}$

In this issue of the Journal, Leijser and colleagues ${ }^{4}$ have used this observational study design to explore any potential association between brain injury and perioperative AT in children with 2 types of CHD, transposition of the great arteries and single-ventricle physiology (SVP). They performed an observational cohort study and a subanalysis of a previous study at 2 clinical centers with different approaches to use of AT, in addition to different approaches in dosing and target therapeutic ranges. They then compared brain injury outcomes between children who received AT and those who did not. Overall, AT was used in $29 \%$ of neonates $(36 / 118)$ with transposition of the great arteries and SVP for the following indications: peripheral and intracardiac thrombosis $(\mathrm{n}=20 ; 56 \%)$, preoperative stroke $(\mathrm{n}=11 ; 30 \%)$, and Blalock-Taussig shunts $(\mathrm{n}=5$; $4 \%$ ). Study results did not demonstrate an increase in white matter injury, ischemic stroke, or subdural and intraventricular hemorrhage in those who received AT preoperatively compared with those not treated. When separating the transposition of the great arteries and SVP groups, however, increased parenchymal injury $(P=.04)$, which was mostly due to ischemic stroke was, demonstrated in patients with SVP who received AT. In addition, Leijser and colleagues ${ }^{4}$ suggest that neonates receiving aspirin and anticoagulation $(\mathrm{n}=5)$ have an increased incidence of subdural hemorrhage $(\mathrm{n}=2 ; 40 \%)$ relative to those infants receiving only anticoagulation; however, the numbers are small.

The results of this study must be interpreted in the context of the type of study design. Observational studies in clinical medicine allow the determination of simple associations, but they cannot establish cause and effect. Because assignments of patients to the treatment and no treatment groups were not randomized and were based on center-specific therapy, major issues with bias must be recognized by the reader, including selection and information bias and confounders (ie, an alternative explanation for study results). ${ }^{5,6}$ All the cases of SVP treated with AT were at a single center, perhaps confounding the results in addition to challenging generalizability. Despite these challenges, observational studies have advantages, including the identification of associations between treatment and outcomes. Demonstration of association between AT therapy and 
brain injury in SVP provides information to further explore safety and efficacy of this treatment regimen and others in prospective multicenter clinical trials.

Importantly, Leijser and colleagues ${ }^{4}$ have highlighted that the "best" stroke therapy for children with CHD is currently unknown, resulting in center-specific approaches. Results of this study demand multicenter prospective studies comparing therapies in children with different types of CHD to prevent brain injury and preserve brain health. ${ }^{2}$

\section{References}

1. Auden WH, Kronenberger L. Viking Book of Aphorisms: A Personal Selection. New York: Viking Press; 1962.

2. Ferriero DM, Fullerton HJ, Bernard TJ, Billinghurst L, Daniels SR, DeBaun MR, et al; American Heart Association Stroke Council and Council on Cardiovascular and Stroke Nursing. Management of stroke in neonates and children: a scientific statement from the American Heart Association/American Stroke Association. Stroke. 2019;50:e51-96.

3. Giglia TM, Massicotte MP, Tweddell JS, Barst RJ, Bauman M, Erickson CC, et al; American Heart Association Congenital Heart Defects Committee of the Council on Cardiovascular Disease in the Young, Council on Cardiovascular and Stroke Nursing, Council on Epidemiology and Prevention, and Stroke Council. Prevention and treatment of thrombosis in pediatric and congenital heart disease: a scientific statement from the American Heart Association. Circulation. 2013;128:2622-703. Erratum in: Circulation. 2014;129:e23.

4. Leijser LM, Chau V, Seed M, Poskitt KJ, Synnes A, Blaser S, et al. Anticoagulation therapy and the risk of perioperative brain injury in neonates with congenital heart disease. J Thorac Cardiovasc Surg. 2019;157:2406-13.e2.

5. Carlson MD, Morrison RS. Study design, precision, and validity in observational studies. J Palliat Med. 2009;12:77-82.

6. Thiese MS. Observational and interventional study design types; an overview. Biochem Med (Zagreb). 2014;24:199-210. 